\title{
The Relationship of Stress and Sleep Quality amongst Cognitive Science Students
}

\author{
CHEONG CAR LYN \& TAN KOCK WAH*
}

\author{
Faculty of Cognitive Sciences \& Human Development, Universiti Malaysia Sarawak, Kota Samarahan, 94300 \\ Sarawak, Malaysia. \\ *Corresponding author: kwtan@unimas.my
}

\begin{abstract}
Stress is a common problem in modern life. Most Malaysian students suffer from high stress levels and poor sleep quality without realising their harmfulness to health and well-being. The major focus of the paper is to examine the relationship between stress and sleep quality among Cognitive Science undergraduate students. This paper also investigates if demographic attributes (gender differences and year of study) affect stress level and sleep quality. The participants of this study comprised 90 Cognitive Science undergraduate students studying at the Universiti Malaysia Sarawak. Data was collected by using the Perceived Stress Questionnaire (Perceived Stress Scale) and Sleep Quality Questionnaire (Pittsburgh Sleep Quality Index). The results of the study showed that there was a weak relationship between stress and sleep quality. Those in the poor sleep category reported higher levels of perceived stress. Moreover, the findings showed that female students had higher stress levels than male students. First year students appeared to experience poorer sleep quality compared to final year students. The study also found no interaction effects between gender and year of study on sleep quality and stress. Further research could be conducted with a bigger population size and in other study programs. Future research could also assess nondemographic factors which might influence stress and sleep quality.
\end{abstract}

Keywords: Gender, perceived stress levels, sleep quality, year of study

Copyright: This is an open access article distributed under the terms of the CC-BY-NC-SA (Creative Commons Attribution-NonCommercial-ShareAlike 4.0 International License) which permits unrestricted use, distribution, and reproduction in any medium, for non-commercial purposes, provided the original work of the author(s) is properly cited.

\section{INTRODUCTION}

Stress is a common problem in modern life. It affects us in many ways and appears inevitable. Stress is not only a problem that is prevalent amongst working adults but students are also especially vulnerable. University life for many students would mean a period that entail new challenges and adjustments which may lead to increased stress for those who are less able to cope. Most Malaysian students suffer from excessive stress (Hj Ramli, Alavi, Mehrinezhad, \& Ahmadi, 2018). Stress refers to the "wear and tear" experienced by the body while it adjusts to pressure or threatening circumstances (Behere, Behere, \& Yadav, 2011) which when serious could lead to detrimental outcomes. News about students ending their lives due to academic stress are not unfamiliar in today's society (Yeoh, 2013).

Sleep is one of man's basic needs, important for health and general well-being. Sleep can help revitalise and rejuvenate the body. Lack of sleep will bring about a series of major health issues such as diabetes and cardiovascular disease. However, there appears to be a common misconception that sleep could somehow be sacrificed for work. University students are easy victims to this misguided belief. In trying to juggle many things at once (academic workload, social life, internship, etc), sleep usually becomes an easy trade-off. The University of Georgia reported that on average most university students did not get enough sleep (The Setonian Editorial Board, 2018). If severe, this could lead to mental problems such as anxiety, metabolic disorders such as obesity and cardiovascular disorders such as hypertension and sudden cardiac arrest (Bernama, 2016; Tan, 2018). Accumulated "sleep debt" will occur if university students spend their night with only one to two hours of sleep (Omar et al., 2012), which then leads to excessive daytime sleepiness. A study of sleep quality among university students reported that $67 \%$ of students experienced sleep disturbances and poor quality of sleep (Omar et al., 2012). Good sleep quality is important and could enhance cognitive functioning such as attention, decision making, learning and memory (Seun-Fadipe \& Mosaku, 2017). 


\section{Demographic attributes and stress}

Anuradha, Dutta, Raja, Sivaprakasam, and Patil (2017) discovered that female students had higher stress levels. This could be due to higher academic stress faced at the higher education level and a greater likelihood of facing challenges in seeking job opportunities upon graduation (Shah, Hasan, Malik, \& Sreeramareddy, 2010). This was supported by Sani et al. (2012), which found the highest prevalence of stress amongst females in their second year of study. This increased level of stress indicated a decrease in psychological health amongst students which may diminish learning and performance. However, a study found that interaction between gender and year of study with stress was not significant (Ramteke \& Ansari, 2016). Hence, more work needs to be carried out to further clarify the relationship between gender and stress (Anbumalar, Agines, Jaswanti, Priya, \& Reniangelin, 2017).

\section{Demographic attributes and sleep quality}

Seun-Fadipe and Mosaku (2017) argued that gender and year of study contributed to poor sleep quality. They also reported that female students had better sleep quality compared to their male counterparts. Seun-Fadipe and Mosaku (2017) also found that sleep quality was worst amongst students in their final year of study. This contradicted Correa, Oliveira, Pizzamiglio, Ortolan, \& Weber, (2017), which noted the highest amount of sleep problems during students' early study years. Meanwhile, Tsai and Li (2004) showed that female students went to bed earlier, woke up earlier and had longer sleep latency, more awakenings, and poorer sleep quality than male students. Yet Omar et al. (2012) showed no gender difference in terms of sleep quality.

\section{Objectives}

This study attempts to identify the relationship between stress and sleep quality among Cognitive Science undergraduate students based on gender and year of study at the Universiti Malaysia Sarawak. In particular, the study objectives were:

1. To study the relationship between stress and sleep quality among students;

2. To study if demographic attributes (gender and year of study) affect sleep quality;

3. To identify if demographic attributes (gender and year of study) affect stress level.

\section{MATERIALS \& METHODS}

The present study is a correlational study conducted at the Universiti Malaysia Sarawak. The sample consisted of 90 Cognitive Science undergraduate students. These students were randomly selected from the pool of Cognitive Science students at the Faculty of Cognitive Sciences and Human Development. A consent form was signed by students before answering the questionnaire.

\section{Perceived Stress Scale (PSS)}

The 10-item version was used in this study. Each item was scored using a 5-point rating scale from 0 (never) to 4 (very frequent). Higher scores corresponded to higher perceived stress. The perceived stress level was analysed by quartiles of perceived stress as done in previous studies. The first quartile represented the students not/less stressed, with a PSS score of 0 to 13; the second quartile had a PSS score of 14 to 26, and the third quartile had a PSS score of 27 to 40. From a past study, Cohen, Kamarck and Mermelstein (1983) reported that the convergent validity of PSS-10 instrument was moderate with a reliability rating of 0.78 .

\section{The Pittsburgh Sleep Quality Index (PSQI)}

The Pittsburgh Sleep Quality Index (PSQI) is a self-rated instrument that measures sleep quality over a month period. The index comprised of 19 items, combined to form 7-component scores. The components include subjective sleep quality, sleep latency, sleep duration, habitual sleep efficiency, sleep disturbances, use of sleep medication, and daytime dysfunction. Scoring is based on 0-3 Likert scale which is 0 (no difficulty) to 3 (severe difficulty). The 7-component scores were then added to yield a global score which ranged from 0 to 21 . The overall PSQI global score correlation coefficient for test-retest reliability was 0.87 . The PSQI reported high validity, 
internal consistency and a reliability coefficient with Cronbach's alpha of 0.83 for its seven components (Buysse, Reynolds III, Monk, Berman, \& Kupfer, 1989).

\section{Data analysis}

Data was collected and analysed using The Statistical Package for the Social Science (SPSS) version 24. Descriptive statistics and inferential statistics were performed in this study. A Pearson's Product-Moment Correlation (' $r$ ') Test was performed to examine the relationship between stress and sleep quality amongst students. A Two-way ANOVA analysis was also done to investigate if demographic attributes (gender and year of study) affected sleep quality and stress level.

\section{RESULTS}

A total of 90 respondents were randomly chosen for this research. There were 29 male respondents (32.3\%), and 61 female respondents $(67.8 \%)$. The respondents comprised of the first, second and third year students. Each category had 30 respondents $(33.33 \%)$ respectively. Meanwhile, the breakdown of samples in terms of CGPA is summarised in Table 1.

Table 2 presents the stress levels and sleep quality of respondents. From the analysis, most respondents had high $(25.6 \%, \mathrm{n}=23)$ or moderate stress levels $(71.1 \%, n=64)$ whilst only a minority of them had a low level of stress $(4.4 \%)$. As for global PSQI score (sleep quality), a majority of students $(n=67)$ had experienced poor sleep quality $(74.4 \%)$.

A Pearson correlation test was conducted to determine if there was a relationship between stress with sleep quality amongst students. The result reported stress scores of $\mathrm{M}=2.20, \mathrm{SD}=0.52$ while sleep quality registered $\mathrm{M}=0.74, \mathrm{SD}=0.439$. Referring to Table 3, the result of the correlation analysis was $\mathrm{r}=0.286, \mathrm{p}=0.006$. The null hypothesis was rejected. Albeit weakly related, the result nevertheless suggested that higher stress level would result in poor sleep quality.

A two-way ANOVA was conducted to examine the influence of two independent variables (gender, year of study) on the sleep quality of students. Gender was measured in two dimensions (male, female) whilst year of study consisted of three levels (first year students, second year students, third year students). Only the year of study factor was found to be statistically significant at the .05 significance level. The main effect for gender yielded $\mathrm{F}(1,84)=2.911$, $\mathrm{p}>0.05$, indicating that the effect for gender was not significant (male $\mathrm{M}=0.66, \mathrm{SD}=0.484$; female $\mathrm{M}=0.79$, $\mathrm{SD}=0.413)$. The main effect for year of study yielded $\mathrm{F}(2$, $84)=2.911, \mathrm{p}<0.05$, indicating a significant difference amongst first year students $(\mathrm{M}=0.87, \mathrm{SD}=0.346)$, second year students $(\mathrm{M}=0.60, \mathrm{SD}=0.498)$ and third year students $(\mathrm{M}=0.77, \mathrm{SD}=0.430)$. The interaction effect (gender*year of study) was not significant, with $\mathrm{F}(2,84)=2.090, \mathrm{p}=$ $0.130, \mathrm{p}>0.05$. These results are shown in Table 4 and Table 5 .
Table 1. Summary of Demographic Characteristics

\begin{tabular}{lcc}
\hline Item & $\mathbf{n}$ & $\%$ \\
\hline $\begin{array}{l}\text { Gender } \\
\text { Male }\end{array}$ & 29 & 32.2 \\
Female & 61 & 67.8 \\
\hline Year of Study & & \\
Year 1 & 30 & 33.3 \\
Year 2 & 30 & 33.3 \\
Year 3 & 30 & 33.3 \\
\hline Cumulative Grade Points Average & & \\
Below 2.0 & 1 & 1.11 \\
$2.00-2.49$ & 4 & 4.44 \\
$2.50-2.99$ & 23 & 25.56 \\
$3.00-3.49$ & 37 & 41.11 \\
$3.50-4.00$ & 25 & 27.78 \\
\hline
\end{tabular}

Table 2. Perceived Stress Scale and Global PSQI Score (Sleep Quality)

\begin{tabular}{lll}
\hline Item & n & $\%$ \\
\hline & & \\
Perceived Stress Scale & 4 & 4.4 \\
Low stress & 64 & 71.1 \\
Moderate stress & 22 & 24.4 \\
High Perceived stress & & \\
\hline
\end{tabular}

Global PSQI Score (Sleep Quality)

Good sleep quality $23 \quad 25.6$

\begin{tabular}{lll} 
Poor sleep quality & 67 & 74.4 \\
\hline
\end{tabular} 
Table 3. Correlation between Stress with Sleep Quality

\begin{tabular}{|c|c|c|c|}
\hline & & Stress & Sleep quality \\
\hline \multirow{3}{*}{ Stress } & Pearson Correlation & 1 & $.286^{* *}$ \\
\hline & Sig. (2-tailed) & & .006 \\
\hline & $\mathrm{N}$ & 90 & 90 \\
\hline \multirow{3}{*}{ Sleep quality } & Pearson Correlation & $.286^{* *}$ & 1 \\
\hline & Sig. (2-tailed) & .006 & \\
\hline & $\mathrm{N}$ & 90 & 90 \\
\hline
\end{tabular}

Table 4. Mean and SD for Sleep Quality Scores.

\begin{tabular}{clcccc}
\hline Gender & Year of Study & Mean & Std. Deviation & N \\
\hline \multirow{4}{*}{ Male } & 1st year & .92 & .289 & 12 \\
& 2nd year & .33 & .500 & 9 \\
& 3rd year & .63 & .518 & 8 \\
\cline { 2 - 5 } & & Total & .66 & .484 & 29 \\
\hline \multirow{6}{*}{ Female } & 1st year & .83 & .383 & 18 \\
& 2nd year & .71 & .463 & 21 \\
& 3rd year & .82 & .395 & 22 \\
\cline { 2 - 6 } & & Total & .79 & .413 & 61 \\
\hline \multirow{6}{*}{ Total } & 1st year & .87 & .346 & 30 \\
& 2nd year & .60 & .498 & 30 \\
& 3rd year & .77 & .430 & 30 \\
\cline { 2 - 5 } & & Total & .74 & .439 & 90 \\
\hline
\end{tabular}

Table 5. Two-Way ANOVA analysis on the influence of gender and year study on sleep quality

\begin{tabular}{lrrrrrr}
\hline \multicolumn{1}{c}{ Source } & \multicolumn{1}{c}{$\begin{array}{c}\text { Type III } \\
\text { Sum of } \\
\text { Squares }\end{array}$} & df & Mean Square & \multicolumn{1}{c}{ F } & Sig. & $\begin{array}{c}\text { Partial Eta } \\
\text { Squared }\end{array}$ \\
\hline Corrected Model & $2.272^{\mathrm{a}}$ & 5 & .454 & 2.570 & .033 & .133 \\
Intercept & 38.422 & 1 & 38.422 & 217.336 & .000 & .721 \\
Gender & .515 & 1 & .515 & 2.911 & .092 & .033 \\
Year of Study & .659 & 2 & .830 & 4.693 & .012 & .101 \\
Gender*Year of Study & .739 & 2 & .369 & .090 & .130 & \\
Error & 14.850 & 84 & .177 & & & \\
\hline Total & 67.000 & 90 & & & & \\
\hline Corrected Total & 17.122 & 89 & & & & \\
\hline
\end{tabular}

a. R Squared $=.133($ Adjusted R Squared $=.081)$ 
A two-way ANOVA was also conducted on the influence of two independent variables (gender, year of study) on stress scores of students. Gender was measured in two dimensions (male, female) and year of study consisted of three levels (first year, second year, and third year students). Only the gender factor was statistically significant at the .05 significance level. The main effect for gender yielded $F(1,84)=6.436, p<0.05$, indicating a significant difference amongst male students $(M=2.00, S D=0.378)$, and female students $(M=2.30, S D=$ $0.527)$. The main effect for year of study yielded $F(2,84)=2.686, p>0.05$, indicating that the effect for year of study was not significant; first year students $(M=2.17, \mathrm{SD}=0.461)$, second year students $(\mathrm{M}=2.07, \mathrm{SD}=0.450)$ and third year students $(\mathrm{M}=2.37, \mathrm{SD}=0.556)$. The interaction effect (gender*year of study) was not significant, with $F(2,84)=0.490, p=0.614, p>0.05$. These results are shown in Table 6 and Table 7 .

Table 6. Mean and SD for Stress Scores

\begin{tabular}{|c|c|c|c|c|}
\hline Gender & Year of Study & Mean & Std. Deviation & $\mathrm{N}$ \\
\hline \multirow{4}{*}{ Male } & 1st year & 1.92 & .289 & 12 \\
\hline & 2nd year & 1.89 & .333 & 9 \\
\hline & 3rd year & 2.25 & .463 & 8 \\
\hline & Total & 2.00 & .378 & 29 \\
\hline \multirow{4}{*}{ Female } & 1st year & 2.33 & .485 & 18 \\
\hline & 2nd year & 2.14 & .478 & 21 \\
\hline & 3rd year & 2.41 & .590 & 22 \\
\hline & Total & 2.30 & .527 & 61 \\
\hline \multirow{4}{*}{ Total } & 1st year & 2.17 & .461 & 30 \\
\hline & 2nd year & 2.07 & .450 & 30 \\
\hline & 3rd year & 2.37 & .556 & 30 \\
\hline & Total & 2.20 & .502 & 90 \\
\hline
\end{tabular}

Table 7. Two-Way ANOVA analysis on the influence of gender and year study on stress scores

\begin{tabular}{lrrrrrr}
\hline \multicolumn{1}{c}{ Source } & $\begin{array}{c}\text { Type III Sum } \\
\text { of Squares }\end{array}$ & df & Mean Square & F & Sig. & $\begin{array}{c}\text { Partial Eta } \\
\text { Squared }\end{array}$ \\
\hline Corrected Model & $3.205^{\mathrm{a}}$ & 5 & .641 & 2.805 & .022 & .143 \\
Intercept & 357.775 & 1 & 357.775 & 1565.662 & .000 & .949 \\
Gender & 1.471 & 1 & 1.471 & 6.436 & .013 & .071 \\
Year of Study & 1.228 & 2 & .614 & 2.686 & .074 & .060 \\
Gender*Year of Study & .224 & 2 & .112 & .490 & .614 & .012 \\
Error & 19.195 & 84 & .229 & & & \\
\hline Total & 458.000 & 90 & & & & \\
\hline Corrected Total & 22.400 & 89 & & & & \\
\hline
\end{tabular}

a. R Squared $=.143($ Adjusted R Squared $=.092)$

\section{DISCUSSION}

The results of the Pearson's correlation test showed a weak relationship between stress and sleep quality. Participants reported increased levels of stress (total PSS score) in the poor sleep category (PSQI global score $>5$ ). Students attempted to deal with challenging course demands by reducing their sleep time, resulting in poor sleep quality. This was supported by a study conducted by Lund, Reider, Whiting, and Prichard (2010). The study 
suggested that poor sleep quality amongst college students correlated with higher stress levels. Meanwhile, in another related study, Theadom and Cropley (2008) pointed out that chronic stress may result in sleep disturbances and daytime dysfunction.

Meanwhile, according to Astill, Verhoeven, Vijzelaar, and Van Someren (2013), stress level amongst students was rising, contributing to reduced sleep quality especially during the exam weeks. Students appeared to readily give up sleeping time for more studying time. The results of the present study also complement previous findings in that the close interrelationship between stress and sleep demonstrated directionality issues, in which students with poor sleep quality was either secondary to or predictive of stress levels (Ahrberg, Dresler, Niedermaier, Steiger, \& Genzel, 2012).

\section{Demographic attributes and sleep quality}

The present study finds no significant main effect of gender on sleep quality. Omar et al. (2012) obtained similar results. However, as the main effect of year of study was statistically significant, this clearly shows that first year students reported worse sleep quality compared to advanced level students, in line with Correa et al. (2017). One of the possible reasons was first year students needed to go through a transitional period of change. Students who first entered university may find themselves having to adapt to living away from home and cope with life management and university work. Hence, they would likely cope better once settled in, usually in the subsequent years of university study. For the interaction effect (gender*year of study), no interaction was found between them.

\section{Demographic attributes and stress}

The present study reported a statistically significant difference in the main effect of gender on stress. Female students appeared to report higher stress than male students owing to the difference in male and female response to stress. According to Stahle (2015), male showed a "fight or flight" mentality when stressed, and they appeared to cope with stress better. One plausible reason why females tended to suffer more from stress could be attributed to their hormonal system which make them emotionally sensitive. Generally, increased level of stress entailed a decline in psychological health and diminished learning (Anuradha et al., 2017). This result was consistent with the previous study where female students reported higher levels of stress than their male counterparts (Shah et al., 2010). Meanwhile, the main effect of year of study on stress showed no significant difference. This appeared to contradict the previous study, e.g. Anuradha et al. (2017) which demonstrated that final year students succumb to stress more easily than the first year students. On the other hand, Ramteke and Ansari (2016) showed that first year students suffered more from stress compared to students from a higher level of studies. As for the interaction effect, gender*year of study, the finding did not find evidence of interaction between these two variables. This finding was supported by Ramteke and Ansari (2016) where it was shown that interaction between gender and education level was not significant.

\section{CONCLUSIONS}

The study found a significant relationship between stress and sleep quality among Cognitive Science undergraduate students. However, no interaction effect was found between gender and year of study on sleep quality as well as gender and year of study on stress. Due to the limited scope of the study, future research ought to be conducted with a more sizeable sample and amongst different academic programmes. 


\section{REFERENCES}

Ahrberg, K., Dresler, M., Niedermaier, S., Steiger, A., \& Genzel, L. (2012). The interaction between sleep quality and academic performance. Journal of Psychiatric Research, 46(12), 1618-1622. DOI:10.1016/j.jpsychires. 2012.09.008.

Anbumalar, C., Agines, D. P., Jaswanti, V., Priya, D., \& Reniangelin, D. (2017). Gender differences in perceived stress levels and coping strategies among college students. The International Journal of Indian Psychology, 4(4), DOI:10.25215/0404.103.

Anuradha, R., Dutta, R., Raja, J. D., Sivaprakasam, P., \& Patil, A. B. (2017). Stress and stressors among medical undergraduate students: A cross-sectional study in a private medical college in Tamil Nadu. Indian Journal of Community Medicine: Official Publication of Indian Association of Preventive \& Social Medicine, 42(4), 222-225. DOI:10.4103/ijcm.ijcm_287_16.

Astill, R. G., Verhoeven, D., Vijzelaar, R. L., \& Van Someren, E. J. W. (2013). Chronic stress undermines the compensatory sleep efficiency increase in response to sleep restriction in adolescents. Journal of Sleep Research, 22(4), 373-379. DOI:10.1111/jsr.12032.

Behere, S., Behere, P., \& Yadav, R. (2011). A comparative study of stress among students of medicine, engineering, and nursing. Indian Journal of Psychological Medicine, 33(2), 145. DOI:10.4103/0253-7176.92064.

Bernama (2016). Mental health of Malaysian students cause of worry: Health Ministry. New Straits Times. Retrieved March 13, 2021 from https://www.nst.com.my/news/2016/09/172683/mental-health-malaysianstudents-cause-worry -health-ministry.

Buysse, D. J., Reynolds III, C. F., Monk, T. H., Berman, S. R., \& Kupfer, D.J., (1989). The Pittsburgh Sleep Quality Index: A new instrument for psychiatric practice and research. Psychiatry Research, 28(2), pp193213. DOI: $10.1016 / 0165-1781(89) 90047-4$.

Cohen, S., Kamarck, T., \& Mermelstein, R. (1983). A global measure of perceived stress. Journal of Health and Social Behavior, 24(4), 385-396. DOI:10.2307/2136404.

Correa, C. D. C., Oliveira, F. K. D., Pizzamiglio, D. S., Ortolan, E. V. P., \& Weber, S. A. T. (2017). Sleep quality in medical students: a comparison across the various phases of the medical course. Jornal Brasileiro de Pneumologia, 43(4), 285-289. DOI:10.1590/s1806-37562016000000178

Hj Ramli, N., Alavi, M., Mehrinezhad, S., \& Ahmadi, A. (2018). Academic stress and self-regulation among university students in Malaysia: Mediator role of mindfulness. Behavioral Sciences, 8(1), 12. DOI:10.3390\% 2Fbs8010012

Lund, H. G., Reider, B. D., Whiting, A. B., \& Prichard, J.R. (2010). Sleep patterns and predictors of disturbed sleep in a large population of college students. Journal of Adolescent Health, 46(2), 124-132. DOI:10.1016/j. jadohealth.2009.06.016

Omar, A., Humam, H., Lubna, M., Fatima, S., Alak, K. H., Rizwana, B. S., Shatha, A. S., \& Faheem, A. K. (2012). Sleep quality among university students in the UAE. Gulf Med. Univ. : Proc. 2012; (6-May): 193-199.

Ramteke, P. V. \& Ansari, R. J. (2016). Stress and anxiety among first year and final year engineering students. International Journal of Advanced Research in Education \& Technology, 3(4).

Sani, M., Mahfouz, M., Bani, I., Alsomily, A., Alagi, D., \& Alsomily, N. (2012). Prevalence of stress among medical students in Jizan University, Kingdom of Saudi Arabia. Gulf Medical Journal, 1(1), 19-25.

Seun-Fadipe, C. T. \& Mosaku, K. S. (2017). Sleep quality and academic performance among Nigerian undergraduate students. Journal of Systems and Integrative Neuroscience, 3(5). DOI:10.15761/jsin.10001 79.

Shah, M., Hasan, S., Malik, S., \& Sreeramareddy, C. T. (2010). Perceived Stress, sources and severity of stress among medical undergraduates in a Pakistani Medical School. BMC Medical Education, 10(1), 2. DOI:10. 1186/1472-6920-10-2.

Stahle, T. (2015). Why women are more stressed than men. Retrieved May 16, 2019 from https://www. deseretnews.com/article/865626399/Why-women-are-more-stressed-than-men.html

Tan, S. C. (2018). Survey says: 9 out of 10 Malaysians suffer from sleep problems. Retrieved November 20, 2018 from https://www.star2.com/health/2018/05/17/malaysians-jsuffer-sleep-problems/

Theadom, A. \& Cropley, M. (2008). Dysfunctional beliefs, stress and sleep disturbance in fibromyalgia. Sleep Medicine, 9(4), 376-381. DOI:10.1016/j.sleep.2007.06.005.

The Setonian Editorial Board. (2018). College students aren't getting enough sleep. Retrieved November 19, 2018 from http://www.thesetonian.com/2018/09/19/college-students-arent-getting-enough-sleep/

Tsai, L. L. \& Li, S. P. (2004). Sleep patterns in college students: Gender and grade differences. Journal of Psychosomatic Research, 56(2), 231-237. DOI:10.1016/s0022-3999(03)00507-5.

Yeoh, W. (2013). College student falls to her death. Retrieved March 11, 2021 from https://www.thestar.com.my/ news/nation/2013/08/29/college-student-falls-to-her-death-girl-believed-to-be-suffering-from-examstress/ 